\title{
Creation and Sharing of Human Anatomy Multimedia Education Outputs across Medical and Biomedical Studies
}

\author{
Jaroslav Majerník ${ }^{1 *}$, Monika Michalíková ${ }^{2}$, Ivan Staško ${ }^{2}$ \\ 1 Department of Medical Informatics, Faculty of Medicine, Trieda SNP 1, 04011 Košice, Slovak Republic \\ 2 Department of Biomedical Engineering and Measurement, Faculty of Mechanical Engineering, Letná 9, 04200 Košice, Slovak Republic
}

\begin{abstract}
Education of human anatomy has a long history and as one of the core subjects in medicine and biomedicine it was taught using mostly traditional teaching methods. However, advances in information and communication technologies brought various modernizing approaches to present individual topics in more illustrative and attractive ways even in presence and distance teaching forms. Due to these facts, there are extensive discussions about suitable methods of delivering anatomical knowledge between professionals all around the world. It is because a deep understanding of anatomy is essential for later safe clinical practice. The lack of cadavers, teaching hours in curricula, resources but also increasing number of students forced us to change present teaching methods to more sophisticated alternatives utilizing combination of dissections and available imaging and multimedia resources. Therefore, the methodology to support teaching of anatomy and the system to share our multimedia education outputs of human anatomy across faculties were developed and integrated into curricula.
\end{abstract}

Keywords: Education; multimedia; virtual projection; human anatomy

\section{Introduction}

Human anatomy represents the oldest medical subject that was involved in traditional medical and biomedical education. The subject itself utilized various teaching and learning methods during history [1]. Traditional didactic lectures followed by cadaveric dissections were gradually replaced by plastic specimens, models, demonstrations and later more and more by computerized modeling and simulation techniques. Except of others, the changes were aimed to improve students' visual-spatial thinking, enhance deep learning and stimulate long memory [2].

Deep understanding of anatomy is crucial for competent clinicians in all clinical professions and technicians in biomedical branches [3, 4]. However, to find the most effective teaching form is a big challenge for anatomists, especially in the time when many medical schools, due to the various personal and financial restrictions, reduce number of teaching hours devoted for anatomy. Also, medical students often recognize that poor knowledge of anatomy obtained during trainings in first years of the study cause problems to develop their clinical skills in higher study years when entering clerkships and/or clinical praxis. Resulting medical incompetence may lead to serious medical, social and economic problems as anatomical errors are reported as significant factors that may reduce the number of avoidable deaths. 
In general, the recent teaching in anatomy combines didactic teaching, cadaver dissections, inspection of prosected specimens, use of models, computer-based learning and living and radiological anatomy [5], [6]. On the other hand, learning of anatomy is a process where initial learning is present, followed by the forgetting, restructuring and applying phases [7]. Several studies pointed out that students benefit from visualized structures and imaging techniques [8]. Based on the results of our previous activities to modernize teaching and learning of anatomy [9, 10] and respecting all above mentioned facts we decided to create multimedia education outputs that meet requirements of our curricula and are suitable for student centered approach [11, 12].

\section{Material and Methods}

Teaching of anatomy at our faculty was based mostly on memorizing of individual systems anatomical structures using textbooks. In this manner, teachers and students missed convenient illustrations helping to fix important structural information. Education was aimed to absorb systemic anatomy without emphasis on relations to surrounding structures and their localization in human body. Latter, the curriculum involved regional anatomy and in combination with dissections it was more effective approach. The lack of cadavers forces us to create well illustrated textbooks and especially multimedia education materials. Except of teaching periods the students are allowed to use such materials also in repetition and self-learning. Access to the materials including movies, 3D models and animations improve not only the quality of education but also the quality of preparation for responsible clinicians and health care professionals.

The scheme of modernized education of anatomy involves traditional lecturing with explanation, exercises in dissecting rooms, study of anatomical structures in computer lab, lecturing with 3D virtual projection as well as on-line access to education multimedia outputs for distance and self-learning. Figure 1 shows principle how these components are integrated into the education of anatomy.

Main improvements are based on audiovisual education materials offered to the students in various teaching forms as shown in Figure 1.

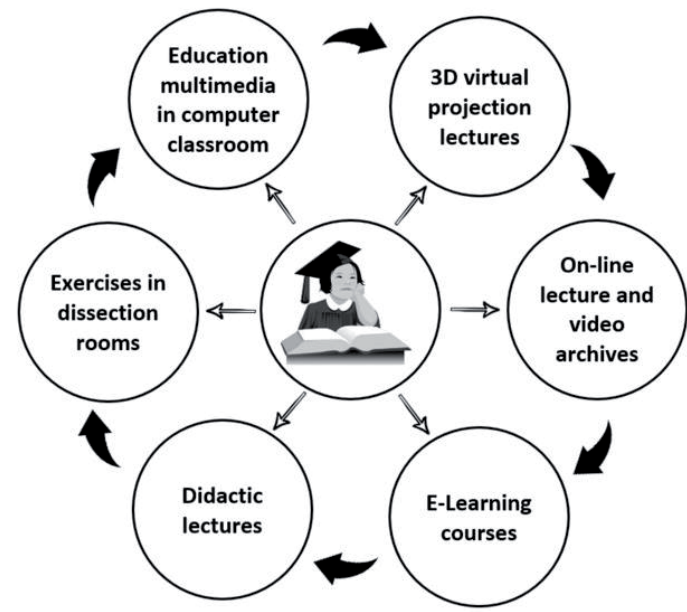

Fig. 1: Methods integrated into education of human anatomy.

Combination of these forms can be efficiently used in both face-to-face and distance teaching forms to deliver knowledge to the students and for self-repetition as well. Technological background supports systematic access to the lectures, images, animations and education movies prepared and commented by our teachers, that exactly match the curriculum of the course. The most desired records of dissections realized in our conditions are integrated into all above mentioned teaching forms in the way that allows to substitute deficiency of cadavers if it happen during teaching periods with large groups of students. Anyway, the dissections remain still the most important part of education.

\subsection{Video-clips}

\section{Results}

To develop anatomically demonstrative and useful educational video-clips we started with recording of dissections realized at the Department of Anatomy. These new video record are realized in both 2D and 3D forms to be able to select the best scenes for the final educational versions and to use it in off-line and on-line tools. Individual videoclips, describing particular human body systems and structures are presentment as separate educational parts. However, they are stored and archived for upcoming faculty's multimedia atlas of human body once all body systems will be processed. Particular scenes required cadavers suitable also for dissections in practical teaching. Thanks to the activities of our anatomist the 
scenes were recorded from several cadavers and combined anywhere where it was convenient to obtain the most illustrative output.

The anatomical structures of upper and lower limbs were processed as first. Also the additional explanatory material was added into the video sequences to explain particular terms, specifications and relationships. This was done as combination of descriptive texts as well as audio comments of our teachers. The video-clips are available to all our students via computers in department's computer lab located close to the dissection rooms. This allows students to study particular details through multimedia prior to practical dissections. Furthermore, the compressed sequences are used in on-line education resources as video equipped lectures given to the students as additional material of printed textbooks. Recently the structures of thorax, abdomen, pelvis, head and neck are recorded and processed.

\subsection{D virtual projection}

To make didactic lectures more demonstrative and attractive we designed teaching materials with strong emphasis on teaching content, interaction with students and effective evaluation tools. Therefore, the 3D virtual projection system was implemented into to the lecturing process. However, its main aim is not to replace but to support traditional form of education. The system is installed in the lecture room with the capacity of 200 students and its principle scheme is shown in Figure 2.
Wearing anaglyph glasses, the students feel an existence of 3D space is it is in cinemas and they are allowed to study human body systems in much bigger proportions than it is on small computer screens. Basically, the system is composed of special large projection screen, pair of projectors, cluster of three powerful computers and theatre sound system. Other components of the system include teacher's workstation and 3D cameras. The large screen projection shows final stereoscopic education movies and/or animations during lectures to the audience. Teacher's workstation allows us to process real captured content as well as digital animations and to prepare required teaching content. 3D camera system is used to record real 3D content (e.g. dissections or surgery interventions).

Scenes of 3D animated education material were created from model of human body bought together with the 3D system. The model itself is divided into the several parts, e.g. muscles, bones, nervous system, vascular system etc. Teaching structure of the human body are loaded into the SuperEngine (software to create scenes and to synchronize individual parts of the body system) according to the aims of presented topics.

Teachers/users can use the functionalities of the engine to make selected parts highlighted, transparent or invisible directly during lectures. Controlling using space mouse facilitate to organize movements, change viewing angles and preparation all the necessary effects in the scene

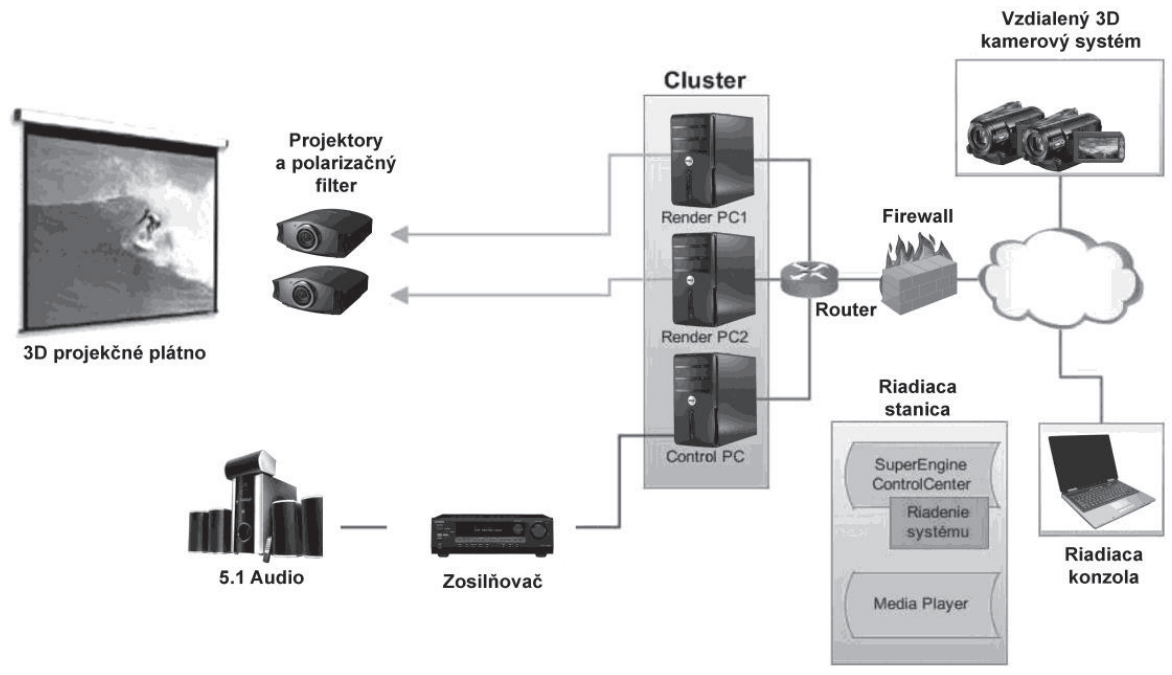

Fig. 2: Scheme of virtual projection used in lecture hall. 
in real time. All scenes that are prepared before the lecture are complemented by texts and audio records and saved as dynamic 3D outputs. These are used in all forms of teaching and learning as it was denoted in Figure 1.

The system also integrates combination of 2D and 3D content recorded from dissections. Materials are presented without the need to change glasses the users wear while watching education materials. At the moment, the most preferable way to use the system functionalities during lectures is presentation of prearranged materials. It's because the teachers do not want to spend any time by managing the scene in real time. However, the main reasons are that they worry to use it as something new and difficult and also there is a need to be skilled in using of the space mouse.

\subsection{On-line access portal}

The faculty's web portal of multimedia support in the education of clinical and health care disciplines (portal.If.upjs.sk) was used as the most convenient platform to share finished or partially finished multimedia outputs to the students and interesting public. Portal represent a unique platform to share multimedia education material for all clinical as well as preclinical courses at the faculty.

Based on the video gallery principles, the individual multimedia materials are published on the portal in articles as embedded movies [13]. Video gallery located in the body of the article uses Video LightBox technology to share movies in a well-arranged and attractive way as well. Video LightBox is an intuitive wizard program, available for free for non-commercial use, allowing adding videos to almost any website with stylish popup video effects. This beautiful product helps us to generate source codes to embed particular video to the website in a few clicks. In general, it is necessary just to add video, to specify the template for video popup and video thumbnail appearance and to publish the result. Except of thumbnail, each educational video is equipped with the title and the name of the speaker/author. Individual video files can be stored in external servers or directly in the portal's repository. We did not specify any restrictions to access individual lectures as these should be available for wider public. However, respecting principles of the portal, the access rights can be specified in the same way as it is in the case of any other educational attachment. In this case, the content can be set to be available for various groups of users, including:

- nonregistered anonymous users,

- registered anonymous users who accept the terms of use within his/her registration,

- users of MEFANET network, i.e., students or teachers from any Czech or Slovak medical faculty,

- users of local university or faculty, whose affiliation to that university/faculty has been verified at the portal or via the local information system of that university/faculty,

- users to whom attachments are made available only on the author's explicit consent.

An example of the anatomy lecture published at the faculty' portal equipped with 3D transformed animation is shown in Figure 3. Interconnection of another medical faculties' portals allows to share these materials at international level across all faculties integrated in MEFANET network [14], [15], [16]. Structure of this network is shown in Figure 4.

The idea of the shared e-publishing system is based on a set of standalone web portals rather than on a centralized application hosted for all medical schools, what might be an inflexible and more vulnerable alternative solution. Each portal instance represents an independent publication media with its ISSN code and an editorial board. Local metadata describing the digital educational contents are replicated regularly to the central gateway.

There are three fundamental elements which have to be kept rigid on the parts of the local administrators: 1. Medical disciplines linker, 2.

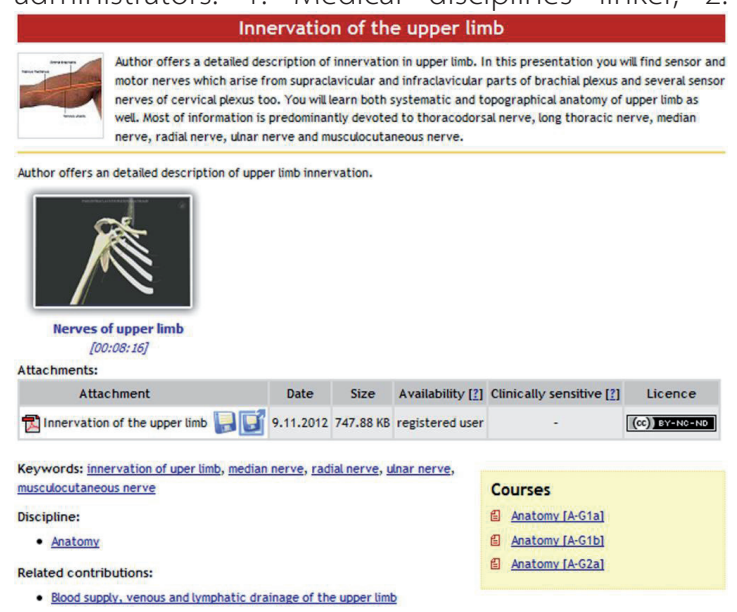

Fig. 3: Example of anatomy lecture published at the faculty's portal 


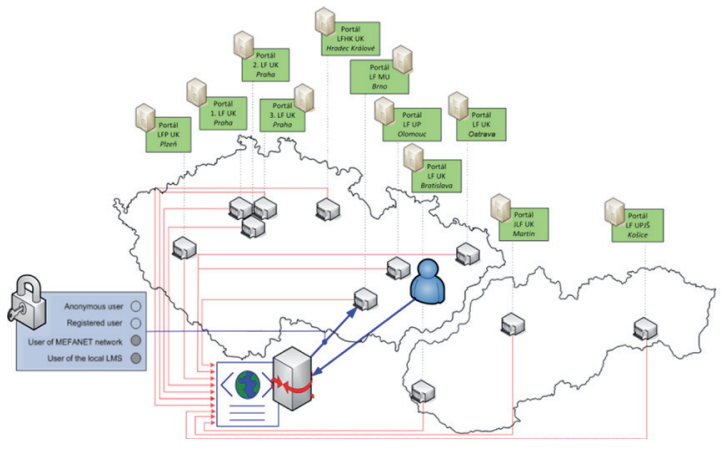

Fig. 4: Interconnection of technical infrastructure to share medical education content across medical faculties.

Authentication - authorization framework and 3. Multidimensional quality assessment. The other features, properties, functionalities can be adapted or localized to meet the needs of the particular schools.

\section{Conclusions}

We developed and integrated a group of technological innovation onto the education of human anatomy at our faculty. Our activities were aimed to increase interest of students in presented topics, to stimulate visual memory, to associate new audio-visual materials with traditional education and to offer suitable materials for self-study.

Respecting the principles of processes used to increase the ability to remember ideas, where the association, visualization, concentration and repetition are involved, we were able to offer more illustrative and explanatory education materials to our student. However, better quality of 3D cameras will be needed to improve our outputs and to be able to capture as small details as possible.

Based on students' responses, the combination of 2D and 3D movies and animations was recognized as very efficient form to make study of individual anatomy topics more attractive. The students can watch scenes as many times they need, even before exercises in dissecting rooms, so it makes our teaching process easier.

The first results of our work also convinced us that the students' abilities to understand body composition, topography of anatomical structures as well as functions and interactions of individual body systems were improved as they achieved better study results. Students appear to learn more effectively when multimedia approaches are integrated in teaching and learning activities. Comparing results of another works in this area we have to agree that no single teaching tool has been found to meet the curriculum requirements and the best way to teach modern anatomy is to combine multiple pedagogical resources to complement one another.

\section{Acknowledgments}

Results presented in this work were obtained with the support of the national agency's grant KEGA 017UPJS-4/2016 "Visualization of education in human anatomy using video records of dissections and multimedia teaching materials".

\section{References and Notes}

[1] Kurt E., Yurdakul S.E., Ataç A., "An Overview of the Technologies Used for Anatomy Education in Terms of Medical History", Procedia - Social and Behavioral Sciences, Volume 103, 26 November 2013, p. 109-115, http://dx.doi.org/10.1016/j. sbspro.2013.10.314

[2] Naug H.L. et al. "Experiential Learning, Spatial Visualization and Metacognition: An Exercise with the "Blank Page"Technique for Learning Anatomy", Health Professions Education (2016), http://dx.doi.org/10.1016/j.hpe.2016.01.001

[3] Sharma G. et al., "A cadaveric procedural anatomy course enhances operative competence", Journal of Surgical Research, Volume 201, Issue 1, 2016, p. 22-28, http://dx.doi. org/10.1016/j.jss.2015.09.037

[4] Hudák R., Rajtúḱková V., Živčák J. "Automatization of contact pressure measurement between trunk orthosis and patient's body using a matrix tactile sensor", Acta Mechanica et Automatica, Volume 9, Issue 1, 25 July 2015, Pages 38-43

[5] Estai M., Bunt S., "Best teaching practices in anatomy education: A critical review", Annals of Anatomy, (2016), http:// dx.doi.org/10.1016/j.aanat.2016.02.010

[6] Gradl-Dietsch, G., et al., "Multidimensional approach to teaching anatomy - Do gender and learning style matter?", Ann. Anatomy (2016), http://dx.doi.org/10.1016/j. aanat.2016.03.002

[7] Smith C.F., Mathias H.S., "What impact does anatomy education have on clin-ical practice?", Clin. Anat. 24, 2011, p. 113-119, http://dx.doi.org/10.1002/ca.21065.

[8] Wright S.A., Bell, A.L., "Enhancement of undergraduate rheumatology teaching through the use of musculoskeletal ultrasound", Rheumatology, Volume 47, Issue 10, 2008, p. 1564-1566, http://dx.doi.org/10.1093/rheumatology/ ken324.

[9] Bolekova A., "New trends in undergraduate education of human anatomy", MEFANET report 04, Brno, Masaryk University, 2011, ISBN 978-80-210-5539-1, pp. 29-31. 
[10] Majernik J., "3D Virtual Projection and Utilization of Its Outputs in Education of Human Anatomy", Multimedia Technology, ISSN 2327-1078, Vol. 2, no. 1 (2013), p. 1-8.

[11] Kasik, M. Penhaker, V. Novak, R. Bridzik, J. Krawiec, "User Interactive Biomedical Data Web Services Application", ETechnologies and Networks for Development. vol. 171, J. J. Yonazi, E. Sedoyeka, E. Ariwa, and E. ElQawasmeh, Eds., ed, 2011, pp. 223-237, http://dx.doi.org/10.1007/978-3-64222729-5_19.

[12] Tóth T., Živčák J. "A comparison of the outputs of 3D scanners", Procedia Engineering, 2014, Volume 69, pp. 393-401, http://dx.doi.org/10.1016/j.proeng.2014.03.004.

[13] Majerník J. Jarcuška P., "Multimedia support of medical education utilizing on-line archive of video lectures", Studies in Computational Intelligence, Volume 606, 2015, Pages 163174, http://dx.doi.org/10.1007/978-3-319-19147-8_9.

[14] Schwarz D., Štourač P., Komenda M., Harazim H., Kosinová M., Gregor J., Hůlek R., Smékalová O., Křikava I., Štoudek R., Dušek L., "Interactive algorithms for teaching and learning acute medicine in the Network of Medical Faculties MEFANET", Journal of Medical Internet Research, Volume 15, Issue 7, July 2013, Article number e135, http://dx.doi. org/10.2196/jmir.2590.

[15] Komenda M., Schwarz D., Feberová J., Štípek S., Mihál V., Dušek, L., "|Medical faculties educational network: Multidimensional quality assessment", Computer Methods and Programs in Biomedicine, Volume 108, Issue 3, December 2012, Pages 900-909, http://dx.doi.org/10.1016/j. cmpb.2012.05.002

[16] Feberová J., Dostálová T., Polášková A., Seydlová M., "Webbased interactive learning programs for dentistry concept and its evaluation", MEFANET Journal 2013, 1 (1), 5-10.

\section{Biographical notes}

Jaroslav Majerník, doc. Ing., PhD., (born 1977) Head of Department of Medical Informatics at Pavol Jozef Šafárik University, Faculty of Medicine in Košice. He received his Master's degree in the field of Electronics and Telecommunications at Technical University in Kosice, Slovakia in 2000 and Ph.D. degree in Bionics and Biomechanics in 2005. His professional and research interests include biomedical engineering and medical informatics. He is author or co-author of nine books and more than 150 research works and projects in the fields of biomechanics and computer science. He is member of ESMAC, MEFANET Coordination Council, MEFANET Journal Editorial Board, Multimedia Technology Editorial Board and several national societies.

Ivan Staško, MUDr., (born at 18th of May 1960). He studied medicine in Košice at UPJS University.He conducted his attestation tests in the field of orthopedics 1. degree in 1989 and II. degree in 1995. His professional career started at FnLP hospital in Košice, than he was a head of the department at Orthopedics Surgery in Košice- Šaca. Nowadays he continues to work as private doctor and surger focusing on operations of large joints for Svet zdravia network of hospitals within
Slovakia. He is a member of Slovak Orthopaedics and Traumatology association, member of SICOT and EFORT. He is one of the active members of SOTS committee. He also closely works with Technical University Košice in the field of bioengineering for several years. 